\title{
Helminth Records from Eleven Species of Emoia (Sauria: Scincidae) from Oceania ${ }^{1}$
}

\author{
Stephen R. Goldberg, ${ }^{2}$ Charles R. Bursey, ${ }^{3}$ and Robert N. Fisher ${ }^{4}$
}

\begin{abstract}
As part of an ongoing study of the biogeography of helminth parasites of lizards from Oceania, 53 specimens of Emoia (11 species) were examined, as follows: E. atrocostata, E. boettgeri, E. caerulocauda, E. cyanogaster, E. cyanura, E. impar, E. nigra, E. nigromarginata, E. ponapea, E. sanfordi, E. trossula. One species of Digenea, Paradistomoides gregarium, and six species of Nematoda, Hedruris hanleyae, Maxvachonia chabaudi, Parapharyngodon maplestoni, Physalopteroides arnoensis, Spauligodon gehyrae, and Moaciria sp. indet., were found. These helminths have been reported previously from other lizard species. Seventeen new host records and eight new locality records are reported.
\end{abstract}

As PART OF AN ongoing investigation of the biogeography of helminth parasites of lizards in Oceania, we identified helminths from a collection of skinks (Emoia spp.) from Belau, Federated States of Micronesia, Fiji, Tonga, and Vanuatu. The genus Emoia consists of at least 72 species that range from Southeast Asia through the Indo-Australian Archipelago and Oceania (Brown 1991). To our knowledge, only Emoia cyanura, E. nigra, and E. samoensis have previously been reported to harbor helminths (Goldberg and Bursey 1991, Goldberg et al. 2000). The purpose of this paper is to add helminths from 11 species of Emoia to the checklist of endoparasites for lizards from Oceania and to ascertain their distribution on the islands of Oceania. The checklist of endoparasites for lizards from Oceania began with the summaries of helminthological data on geckonid and scincid lizards by Goldberg et al. (1998, 2000) and Goldberg and Bursey (2002).

\footnotetext{
${ }^{1}$ Manuscript accepted 12 November 2004.

2 Department of Biology, Whittier College, Whittier, California 90608.

${ }^{3}$ Department of Biology, Pennsylvania State University, Shenango Campus, Sharon, Pennsylvania 16146.

${ }^{4}$ U.S. Geological Survey, 5745 Kearny Villa Road, Suite M, San Diego, California 92123.
}

Pacific Science (2005), vol. 59, no. 4:609-614

(C) 2005 by University of Hawai'i Press

All rights reserved

\section{MATERIALS AND METHODS}

Eleven species of Emoia $(n=53)$ from Oceania were examined, as follows: E. atrocostata $\left(n=1\right.$, Kobasang Island, Belau, $7^{\circ} 30^{\prime} \mathrm{N}$, $\left.134^{\circ} 30^{\prime} \mathrm{N}\right)$; E. boettgeri $(n=1$, Pohnpei Island, Federated States of Micronesia, $9^{\circ} 0^{\prime}$ $\left.\mathrm{N}, 150^{\circ} 0^{\prime} \mathrm{E}\right)$; E. caerulocauda $(n=8$, Efate Island, Vanuatu, $\left.15^{\circ} 0^{\prime} \mathrm{S}, 168^{\circ} 0^{\prime} \mathrm{E}\right)$; E. cyanogaster ( $n=2$, Efate Island, Vanuatu); E. cyanura $(n=9 ; 4$ from the Kingdom of Tonga, $19^{\circ} 50^{\prime} \mathrm{S}, 174^{\circ} 30^{\prime} \mathrm{W} ; 1$ from Pohnpei Island, Federated States of Micronesia; 4 from Nanuku Island, Fiji, $16^{\circ} 35^{\prime} \mathrm{S}, 179^{\circ} 08^{\prime} \mathrm{E}$ ); E. impar $(n=5 ; 4$ from Efate Island, Vanuatu; 1 from Ugaga Island, Fiji, $18^{\circ} 22^{\prime} \mathrm{S}, 178^{\circ} 13^{\prime}$ $\mathrm{E})$; E. nigra ( $n=11$, Kingdom of Tonga); E. nigromarginata $(n=10$, Efate Island, Vanuatu); E. ponapea $(n=1$, Pohnpei Island, Federated States of Micronesia); E. sanfordi ( $n=1$, Efate Island, Vanuatu); E. trossula $(n=4$, Kingdom of Tonga). Lizards from the Kingdom of Tonga were collected in 1972 and are deposited in the Museum of the South Pacific, Suva, Fiji. Emoia atrocostata, E. boettgeri, and E. ponapea were collected in 1991 and are deposited in the California Academy of Sciences, San Francisco. All other Emoia were collected in 1993 and are deposited in the United States National Museum, Washington, D.C.

Lizards were dissected shortly after capture; helminths were removed and placed in vials of $70 \%$ ethanol; the carcasses were then preserved in $10 \%$ formalin and subsequently 
stored in $70 \%$ ethanol. For lizards from the Kingdom of Tonga, the esophagus, stomach, and small and large intestines were opened and separately searched for helminths under a dissecting microscope. From the other localities, only stomachs were examined. The helminths were examined in 2001, at which time the nematodes were identified after clearing in a drop of glycerol under a coverslip on a microscope slide, and the digeneans were stained with hematoxylin and studied as whole mounts.

\section{RESULTS}

We found one species of Digenea, Paradistomoides gregarium (Dicrocoeliidae), and six species of Nematoda: Hedruris banleyae (Hedruridae), Maxvachonia chabaudi (Cosmocercidae), Moaciria sp. indet. (Heterakidae), Parapharyngodon maplestoni (Pharyngodonidae), Physalopteroides arnoensis (Physalopteridae), and Spauligodon gehyrae (Pharyngodonidae). Prevalence (percentage of host species infected by a helminth species) and mean intensity \pm 1 SD (number of individuals of a helminth species divided by number of infected hosts) are given in Table 1. Voucher specimens of the helminths were deposited in the United States National Parasite Collection (USNPC), Beltsville, Maryland: Emoia atrocostata (Paradistomoides gregarium, USNPC 93732); Emoia boettgeri (Hedruris banleyae, USNPC 93733; Moaciria sp. indet., USNPC 93734); Emoia caerulocauda (Hedruris banleyae, USNPC 93735); Emoia cyanogaster (Hedruris hanleyae, USNPC 93736); Emoia cyanura (Hedruris banleyae, USNPC 93737); Emoia impar (Hedruris hanleyae, USNPC 93738, 93739); Emoia nigra (Hedruris hanleyae, USNPC 93709; Maxvachonia chabaudi, USNPC 93715; Parapharyngodon maplestoni, USNPC 93710; Physalopteroides arnoensis, USNPC 93712); Emoia nigromarginata (Hedruris hanleyae, USNPC 93740); Emoia ponapea (Moaciria sp. indet., USNPC 93741); Emoia sanfordi (Hedruris hanleyae, USNPC 93742); Emoia trossula (Hedruris banleyae, USNPC 93727; Physalopteroides arnoensis, USNPC 93731; Spauligodon gehyrae, USNPC 93728).
DISCUSSION

Paradistomoides gregarium was originally described as Paradistomum magnum from specimens taken from the gall bladder of a gecko, Hemidactylus frenatus, collected in the Philippines by Tubangui (1928). However, Paradistomum magnum was preoccupied, and Tubangui (1929) changed the name to Paradistomum gregarium, which was assigned to its current genus by Travassos (1944). Synonyms include Paradistomum brevis, P. geckonum, $P$. laruei, $P$. magnum, $P$. medicus, $P$. oroterminosus, and P. paloensis. Additional hosts include the agamid lizards Calotes versicolor, Hydrosaurus pustulatus; the gekkonids Cosymbotus platyurus, Gehyra mutilata, G. oceanica, Gekko gecko, Hemidactylus frenatus, H. brookii, Lepidodactylus guppyi, Nactus pelagicus; the lacertid Takydromus sexlineatus; and the scincids Emoia cyanurum, Lipinia noctua, Prasinobaema virens, Sphenomorphus solomonis (Tubangui 1933, Fischthal and Kuntz 1967, Killick and Beverley-Burton 1982). Emoia atrocostata represents a new host record, and Belau is a new locality record.

Hedruris hanleyae was described from the stomach of a gecko, Hemidactylus garnotii, collected in the Cook Islands (Bursey and Goldberg 2000). Additional hosts include Gehyra mutilata, G. oceanica, Hemidactylus frenatus, Lepidodactylus lugubris, L. moestus, and L. paurolepis. Emoia boettgeri, E. caerulocauda, E. cyanogaster, E. cyanura, E. impar, E. nigra, E. nigromarginata, E. sanfordi, and E. trossula represent new host records. Vanuatu and Federated States of Micronesia are new locality records.

Maxvachonia chabaudi was described from individuals pooled from nine species of lizards and one species of snake collected in Australia by Mawson (1972): the gekkonid Pbyllurus milii; the scincids Ctenotus australis, C. labillardieri, C. leae, Egernia whitii, Eulamprus kosciuskoi, Hemiergis peronii, Lerista bougainvillii, Morethia lineoocellata; and the elapid Pseudonaja affinis. Additional Australian hosts include the scincids Ctenotus brooksi, C. leonhardii, C. pantherinus, C. quattuordecimlineatus, C. regius, and Egernia inornata and the varanid Varanus tristis (Jones 1988, Goldberg and 


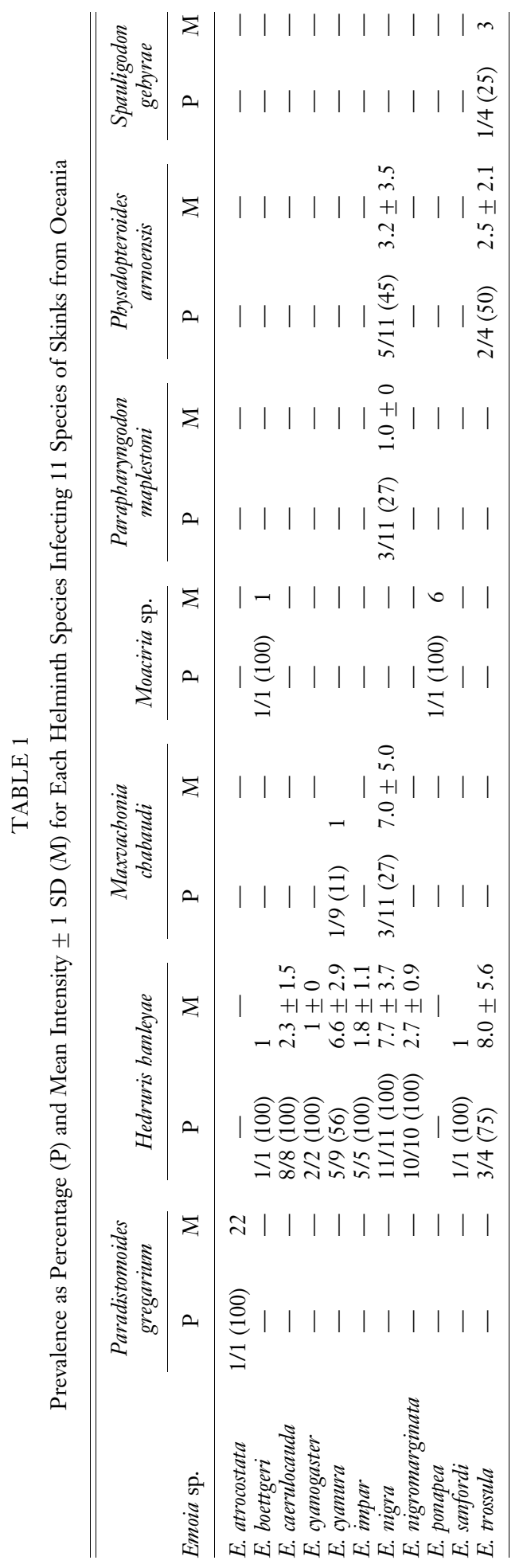


Bursey 1995, 2000, Goldberg et al. 1999). Other reported hosts include Emoia cyanura, Gehyra mutilata, G. oceanica, Lepidodactylus lugubris, and L. paurolepis (Goldberg and Bursey 2002). Emoia nigra represents a new host record. The Kingdom of Tonga is a new locality record.

Moaciria is represented in Australia and Oceania by five species (Gibbons 1979, Jones 1979), four species described from snakes, namely M. butleri, M. chondropythonis, $M$. etnae, M. komodoensis, and one species from a lizard, M. sphenomorphi. Species identification for Moaciria is based upon male caudal morphology. Only females were found in this study; thus identification to species was not attempted. Emoia boettgeri and E. ponapea represent new host records for Moaciria. Federated States of Micronesia is a new locality record.

Parapharyngodon maplestoni was originally described from the intestine of an agamid lizard, Calotes versicolor, collected in Burma by Chatterji (1933). Additional hosts include the agamid Bronchocela cristatellus; the anguid Ophisaurus apodus; the gekkonids Hemidactylus flavoviridis, H. frenatus; and the scincid Glaphyromorphus emigrans (Goldberg and Bursey 2002). Emoia nigra is a new host record. The Kingdom of Tonga is a new locality record.

Physalopteroides arnoensis was described from the intestinal tract of the gecko Lepidodactylus lugubris, collected in the Republic of the Marshall Islands (Bursey and Goldberg 2001). Additional hosts include the gekkonids Lepidodactylus moestus and L. paurolepis (Goldberg and Bursey 2002). Emoia nigra and Emoia trossula represent new host records. The Kingdom of Tonga is a new locality record.

Spauligodon gebyrae was described from the large intestine of the gecko Gebyra oceanica, collected in Guam (Bursey and Goldberg 1996). It has also been reported from Lepidodactylus lugubris. Emoia trossula represents a new host record. The Kingdom of Tonga is a new locality record.

Previous reports of helminths in species of Emoia include Parapharyngodon kartana (Pharyngodonidae) from E. nigra and E. samoensis and Cylindrotaenia decidua (Cestoda:
Nematotaeniidae), Maxvachonia chabaudi, and larvae of Skrjabinoptera sp. (Seuratidae) from E. cyanura (Goldberg and Bursey 1991, Goldberg et al. 2000). Parapharyngodon kartana was described from the scincid Hemiergis peronii by Johnston and Mawson (1941) and is also known from the agamid Ctenophorus fionni; the gekkonid Christinus marmoratus; and a scincid, Lerista sp. (Goldberg and Bursey 1991). Cylindrotaenia decidua was described from the scincid Oligosoma nigriplantare by Ainsworth (1985) and is also known from the scincid Cryptoblepharus poecilopleurus and the gekkonid Gebyra oceanica (Goldberg et al. 2000). Larvae of Skrjabinoptera were also reported from Cryptoblepharus poecilopleurus and Lepidodactylus lugubris (Goldberg et al. 2000).

The 10 species of helminths harbored by species of Emoia are generalists (species capable of infecting more than one species of lizard). For infection by these species, ecological factors related to egg survival may be more important than physiological (host) factors. Species of Hedruris, Moaciria, Parapharyngodon, and Spauligodon have monoxenous life cycles and require the ingestion of an egg before infection can occur; species of Physalopteroides and Skrjabinoptera have heteroxenous life cycles that require the ingestion of the intermediate host; the life cycles of species of Maxvachonia are unknown, although other cosmocercoids produce larvae that utilize skin penetration as a route of infection (Anderson 2000). Trematodes and cestodes have heteroxenous life cycles (Roberts and Janovy 2005). Examination of ecological aspects of the natural history of species of Emoia may give a clue to the differential infection rates by the helminths reported here.

Helminthological examinations of additional species are required before the helminth diversity of lizard species from Oceania can be known and the distribution of helminths among the Pacific islands can be ascertained.

\section{ACKNOWLEDGMENT}

We thank Murray D. Dailey (Marine Mammal Center, Sausalito, California) for 
the nematode samples from the Kingdom of Tonga.

\section{Literature Cited}

Ainsworth, R. 1985. Baerietta decidua n. sp. (Cestoda: Nematotaeniidae) from the New Zealand skink Leiolopisma nigriplantare maccanni Hardy, 1977. N. Z. J. Zool. 12:131-135.

Anderson, R. C. 2000. Nematode parasites of vertebrates: Their development and transmission. 2nd ed. CABI Publishing, Wallingford, United Kingdom.

Brown, W. C. 1991. Lizards of the genus Emoia (Scincidae) with observations on their evolution and biogeography. Calif. Acad. Sci. Mem. 15.

Bursey, C. R., and S. R. Goldberg. 1996. Spauligodon gebyrae n. sp. (Nematoda: Pharyngodonidae) from Gehyra oceanica (Sauria: Gekkonidae) from Guam, Mariana Islands, Micronesia. J. Parasitol. 82:962964.

2000. Hedruris hanleyae n. sp. (Nematoda: Hedruridae) from Hemidactylus garnotii (Sauria: Gekkonidae) from the Cook Islands, Oceania. J. Parasitol. 86:556-559.

- 2001. Physalopteroides arnoensis n. sp. (Nematoda: Physalopteroidea) and other intestinal helminths of the mourning gecko, Lepidodactylus lugubris (Sauria: Gekkonidae), from Arno Atoll, Republic of the Marshall Islands, Oceania. J. Parasitol. 87:135-138.

Chatterji, R. C. 1933. On a new nematode, Parapharyngodon maplestoni gen. nov., sp. nov., from a Burmese lizard. Ann. Trop. Med. Parasitol. 27:131-134.

Fischthal, J. H., and R. E. Kuntz. 1967. Digenetic trematodes of amphibians and reptiles from Fiji, New Hebrides and British Solomon Islands. Proc. Helminthol. Soc. Wash. 34:244-251.

Gibbons, L. M. 1979. Moaciria chondropythonis sp. n. (Heterakidae; Spinicaudinae), a nematode from a Papuan tree python, Chondropython viridis. J. Helminthol. 53:301-306.

Goldberg, S. R., and C. R. Bursey. 1991. Parapharyngodon kartana in two skinks, Emoia nigra and Emoia samoense (Sauria: Scincidae), from Samoa. J. Helminthol. Soc. Wash. 58:265-266.

-1995. Gastrointestinal nematodes of two Australian skinks, Ctenotus regius and Ctenotus schomburgkii (Sauria: Scincidae). J. Helminthol. Soc. Wash. 62:237-238.

- 2000. Intestinal helminths of five species of scincid lizards (Sauria: Scincidae) from Western Australia. Trans. R. Soc. S. Aust. 124:127-133.

- 2002. Gastrointestinal helminths of seven gekkonid lizard species (Sauria: Gekkonidae) from Oceania. J. Nat. Hist. 36:2249-2264.

Goldberg, S. R., C. R. Bursey, and H. Cheam. 1998. Gastrointestinal helminths of four gekkonid lizards, Gehyra mutilata, Gebyra oceanica, Hemidactylus frenatus and Lepidodactylus lugubris from the Mariana Islands, Micronesia. J. Parasitol. 84:12951298.

- 2000. Gastrointestinal helminths of four lizard species from Moorea, French Polynesia. Comp. Parasitol. 67:118-121.

Goldberg, S. R., C. R. Bursey, and S. Hernandez. 1999. Nematodes of two skinks, Ctenotus leonbardii and Ctenotus quattuordecimlineatus (Sauria: Scincidae), from Western Australia. J. Helminthol. Soc. Wash. 66:89-92.

Johnston, T. H., and P. M. Mawson. 1941. Some nematodes from Kangaroo Island, South Australia. Rec. S. Aust. Mus. (Adelaide) 7:145-148.

Jones, H. I. 1979. New species of Moaciria Freitas 1956 (Nematoda: Heterakoidea) from Australian reptiles. J. Helminthol. 53:133-140.

. 1988. Nematodes from nine species of Varanus (Reptilia) from tropical northern Australia with particular reference to the genus Abbreviata (Physalopteridae). Aust. J. Zool. 36:691-708.

Killick, L. M., and M. Beverley-Burton. 1982. Observations on digeneans from lizards (Sauria) in Indonesia (Paradistomum geckonum, Mesocoelium sociale, and Postorchigenes ovatus) with a revision of Paradistomum Kossack, 1910 (Dicrocoeliidae). Can. J. Zool. 60:2093-2106. 
Mawson, P. M. 1972. The nematode genus Maxvachonia (Oxyurata: Cosmocercidae) in Australian reptiles and frogs. Trans. R. Soc. S. Aust. 96:101-108.

Roberts, L. S. and J. Janovy Jr. 2005. Gerald D. Schmidt \& Larry S. Roberts' Foundations of Parasitology. 7th ed. McGraw Hill, Boston.

Travassos, L. 1944. Revisão da familia Dicrocoeliidae Odhner, 1910. Monogr. Inst. Oswaldo Cruz Rio de J. 2.
Tubangui, M. A. 1928. Trematode parasites of Philippine vertebrates. Philipp. J. Sci. 36:351-371.

1929. Paradistomum gregarium, a new name for the trematode Paradistomum magnum. Philipp. J. Sci. 38:443.

. 1933. Trematode parasites of Philippine vertebrates, VI: Descriptions of new species and classification. Philipp. J. Sci. 52:167-197. 